\title{
Corrigendum: Through the eyes of parents: Culture of young children in diverse early learning spaces
}

\section{Authors:}

Aletta J. van $\mathrm{As}^{1}$ (D)

Lorayne A. Excell ${ }^{2}$ (D

Noluthando Magadla ${ }^{3}$ (D)

Neliswa Gqoli ${ }^{3}$ (D)

\section{Affiliations:}

${ }^{1}$ Department of Foundation

Studies: Music Education,

Wits School of Education,

University of the

Witwatersrand,

Johannesburg, South Africa

${ }^{2}$ Department of Foundation

Studies: Early Childhood

Education, University of the

Witwatersrand, Johannesburg,

South Africa

${ }^{3}$ Department of Adult,

Foundation Phase and

Educational Foundations

Education, Faculty of

Educational Sciences, Walter

Sisulu University, Mthatha,

South Africa

Corresponding author:

Aletta van As,

aletta.vanas@wits.ac.za

Dates:

Published: 01 Dec. 2021

How to cite this article: Van As, A.J., Excell, L.A., Magadla, N. \& Gqoli, N. 2021, 'Corrigendum: Through the eyes of parents: Culture of young children in diverse early learning spaces', The Journal for Transdisciplinary Research in Southern Africa 17(1), a1128. https://doi. org/10.4102/td.v17i1.1128

\section{Copyright:}

(C) 2021. The Authors.

Licensee: AOSIS. This work

is licensed under the

Creative Commons

Attribution License.
In the version of this article initially published, Van As, A.J., Excell, L.A., Magadala, N. \& Gqoli, N., 2020, 'Through the eyes of parents: Culture of young children in diverse early learning spaces', The Journal for Transdisciplinary Research in Southern Africa 16(1), a763. https://doi.org/10.4102/ td.v16i1.763, the third author's surname was spelled incorrectly. The correct spelling should be Magadla instead of Magadala.

This correction does not alter the study's findings of significance or overall interpretation of the study results. The authors apologises for any inconvenience caused. 